\title{
Sobre las recaídas, la mentira y la falta de voluntad de los adictos
}

\author{
Tirapu Ustárroz, J.*; LANDA, N.**; Lorea Conde, I.*** \\ * Neuropsicólogo. Servicio de atención neuropsicología-neuropsiquiatría. Clínica Ubarmin. Elcano.Navarra. \\ * Psicólogo clínico. Programa de Prevención de Drogodependencias. Servicios Sociales. Ayuntamiento de Burlada. \\ *** Psicólogo clínico. Programa Eunate para el tratamiento de Adicciones a Estimulantes. Fundación Proyecto Hombre Navarra. Pamplona. \\ Javier Tirapu. Servicio de Neuropsicología. Clínica Ubarmin. 31486 Elcano. Email: jtirapuu@cfnavarra.es
}

\section{RESUMEN}

La labor clínica cotidiana se encuentra mediatizada por principios generales que se aplican a casos análogos. En el caso de los sujetos adictos, su comportamiento suele responder a un patrón conductual identificado como una manifiesta falta de voluntad, tendencia a la mentira y reincidencia en la conducta adictiva. El objeto de este trabajo es indagar en los motivos subyacentes de la conducta del adicto desde la perspectiva de las relaciones cerebro-mente. De esta manera, se explican las recaídas desde una perspectiva de aprendizaje y memoria implícitos que resulta de la exposición a relaciones entre eventos ambientales y que producen ensamblajes celulares creando una predisposición para la acción. En segundo lugar, se trata sobre la mentira desde la necesidad del mantenimiento del "status quo" y del sistema de creencias, relacionándolo con la especialización de ambos hemisferios cerebrales. Así, el hemisferio izquierdo impone su estilo cognitivo basado en la búsqueda de una sensación de coherencia y continuidad, mientras el hemisferio derecho, por el propio efecto neurotóxico de las drogas, no es capaz de imponer un cambio de paradigma. Por último, se plantea la "falta de voluntad" desde la hipótesis del marcador somático, señalando que puede existir una disociación entre conocimiento y conducta, ya que para que exista congruencia es necesaria una emoción acompañante a dicho conocimiento. Esta relación se establece en el sector ventromediano del córtex prefrontal y su afectación produce una incapacidad para establecer balances tras determinadas experiencias, lo que conlleva una dificultad para la toma de decisiones ventajosas para el futuro.

Palabras clave: adicción, marcador somático, autoengaño, recaídas, memoria implícita.

\section{ABSTRACT}

Daily clinical work is under the influence of general principles that are applied to analogous cases. Addictive behaviour is usually identified as lacking willpower, with a tendency to lie and to relapse in the addictive behaviour. The aim of this paper is to inquire into the motives underlying the addictive behaviour from the brain-mind relationship perspective. In this way, the relapses are explained from the point of view of the learning and implicit memory. So, this is the result of the exposure to events that produce cellular assembly originating an inclination to the action. In addition, the addict's lie is explained as a necessity to defend the "status quo" and the belief system in relation with the braining interhemispheric specialisation. So, the left hemisphere imposes its cognitive model that looks for a sense of coherence and continuity. While, the right hemisphere, due to the neurotoxic effect of the drugs, is unable to impose a change of paradigm. Finally, the lack of will is explained from the somatic marker hypothesis showing that a dissociation may exist between knowledge and behaviour. For there to be concordance, an emotion joined to the knowledge is necessary. This union is established in the ventromedial prefrontal cortex and its affectation produces an incapability to establish balance after the experiences. This incapability bears a difficult for future decision-making.

Key words: Addiction, somatic marker, self-deception, relapse, implicit memory.

\section{INTRODUCCIÓN}

$\mathbf{T}$ odo acercamiento a la realidad se ve impregnado de pre-juicios o apriorismos que inevitablemente guían nuestra interpretación y nuestro conocimiento de ella. En un problema tan complejo como la adicción el nivel interpretativo aumenta exponencialmente, posiblemente por la necesidad de explicar aquello que resulta inexplicable. En el tema de las adicciones, estos pre-juicios no han superado un mero 
nivel descriptivo del problema, sin adentrarse en sus causas, lo que hace que estos apriorismos actúen como creencias cercanas al tópico.

La interpretación de la conducta adictiva se halla impregnada de connotaciones negativas que, sin duda, influyen en la intervención terapéutica y menoscaban la relación con el paciente. La causa del problema se explora mediante la entrevista clínica, en la que se establece una continua negociación donde el terapeuta pide y el paciente da. Éste es el pilar básico de la evaluación: la entrega de información fiable por parte del paciente. Pero ¿qué es una información fiable? Al hablar de fiabilidad no se hace referencia solamente a credibilidad y factibilidad, sino a una información que encaje en la manera de entender la patología que el terapeuta trata de abordar. En este sentido, debe reconocerse que en ocasiones se induce al paciente a entregarnos datos que satisfagan nuestro modelo de partida, lo cual produce un efecto tranquilizador en ambas partes.

Con el término "tópicos", se hace referencia a una serie de principios generales que se aplican a todos los casos análogos y de los que se obtiene la prueba para el argumento del discurso. En este sentido, los tópicos operan como esquemas mentales preestablecidos en los que no se cuestiona el cómo y el porqué; simplemente se asumen como verdades.

Esta revisión analiza el tema de las recaídas, caballo de batalla en la intervención en drogodependencias, y gran escollo en los porcentajes de éxitos de los diferentes tratamientos. El modelo de prevención de recaídas de Marlatt y Gordon y el modelo sobre el craving de Tiffany dan una relevante explicación a este fenómeno. Sin embargo, resulta necesario elaborar una ampliación de estos modelos a la luz de los últimos avances en la investigación en neurociencias respecto al funcionamiento cerebral en general y sobre la memoria en particular.

Otro tópico habitual se basa en la afirmación de que el toxicómano miente. A veces, está mentira se explica por sí sola en función de las consecuencias que podría acarrearle decir la verdad. Sin embargo, con frecuencia los beneficios de la mentira no son obvios y, en ocasiones, las mentiras son absurdas por insostenibles. Debemos cuestionarnos si la mentira del adicto es un engaño al terapeuta o un autoengaño en el que la propia percepción de la realidad se ha modificado para sostener un determinado concepto del yo. En cualquier caso, ¿qué correlato cerebral tienen la mentira, la negación y otros fenómenos de distorsión de la realidad que aparecen en los adictos?

Por último, se afirma que un adicto carece de motivación cuando persiste en la conducta de consumo tras someterse a un tratamiento, aunque el paciente asegure su deseo de mantenerse abstinente. Esta situación debería llevar a plantearse qué sucede en el cerebro de una persona para que persista una conducta que conlleva para él importantes consecuencias negativas.

\section{SOBRE LAS RECAÍDAS}

El modelo de prevención de recaídas de Marlatt y Gordon (1) es un instrumento de trabajo de amplia aceptación en los programas de rehabilitación para conductas adictivas. Se trata de un enfoque de tratamiento cognitivo-conductual basado en los principios de la teoría del aprendizaje social de Bandura. Este modelo postula que entre el estado de abstinencia de un sujeto en recuperación y la ocurrencia de una recaída media una situación de alto riesgo, definida como cualquier situación que represente una amenaza para la sensación de control del individuo y aumente el riesgo de una recaída. En este sentido, se identifican tres tipos de situaciones que se encuentran asociadas a la mayoría de las recaídas: los estados emocionales negativos, los conflictos interpersonales y los contextos de presión social. Así, un deficiente manejo de cualquiera de estas situaciones de alto riesgo incrementaría la posibilidad de volver a realizar la conducta adictiva y facilitaría una recaída.

Además, este modelo explica porqué algunas circunstancias, como la ausencia de habilidades de afrontamiento, la inhibición de estas respuestas por la ansiedad, la falta de categorización de la situación como de alto riesgo, los déficits de motivación hacia la abstinencia o la "tentación" de uso de la sustancia, dificultan la adecuada respuesta de afrontamiento ante una situación de riesgo. En presencia de cualquiera de estas circunstancias, la posibilidad de que una situación de alto riesgo progrese hasta una recaída aumenta de manera significativa.

Este enfoque también postula que el craving ocurre en presencia de estímulos externos, que actúan como estímulos condicionados que lo provocan. También plantea que los craving pueden operar de manera enmascarada, permitiendo que ocurran las llamadas "decisiones aparentemente irrelevantes", que acercan al sujeto a una recaída.

Es fácil entender el éxito que este modelo ha tenido entre los clínicos, ya que aporta una explicación comprensible del fenómeno, ofrece herramientas de intervención concretas y sencillas (habilidades sociales, relajación, control de la ira), aportando claridad al confuso fenómeno de las drogodependencias.

No obstante, desde nuestro punto de vista, este enfoque adolece de un carácter marcadamente cognitivo, en el que los factores emocionales se consideran únicamente consecuencia de los aspectos cognitivos. Esta teoría parte de la hipótesis latente en toda la psicología cognitiva: "estímulo $\Longrightarrow$ pensamiento $\Rightarrow$ emo- 
ción", que propugna que para modificar una emoción basta con modificar la cognición que la antecede.

Esta teoría presenta además el riesgo de la "profecía autocumplida". Es probable que al ayudar al paciente a buscar un determinado desencadenante de la recaída, el terapeuta encuentre precisamente aquello que esperaba mediante la incitación inconsciente de las respuestas. Con frecuencia los adictos tienen una percepción mucho más automática de sus recaídas y sobre todo del "efecto de violación de la abstinencia": suelen asegurar que tras el primer consumo no piensan absolutamente nada; de hecho, el problema suelen identificarlo como un impulso intenso con ausencia de razonamiento. Sin embargo, al paciente se le trasmite, de forma directa o indirecta, que uno de los objetivos de su tratamiento es percibir los pensamientos que genera en esos momentos y construir, aunque sea a posteriori, los desencadenantes de una recaída. Por eso, no es extraño que el adicto deseoso de colaborar con su terapeuta termine elaborando unos argumentos que encajen apropiadamente con el punto de partida de su terapeuta.

El modelo de prevención de recaídas de Marlatt y Gordon (2) interpreta el comportamiento de abuso de drogas y las recaídas sobre la base de procesos mentales subyacentes a estos fenómenos. A continuación, realizaremos una lectura crítica, basada en las neurociencias, de algunos de estos procesos mentales a los que se refiere el modelo de prevención de recaídas.

Algunos estudios de neurofisiología animal han puesto de manifiesto la relevancia de la función de un conjunto de estructuras cerebrales, entre las que destaca el núcleo accumbens, para el funcionamiento coordinado de un grupo de circuitos córtico-subcorticales en las conductas apetitivas $(3,4,5)$. Este núcleo realiza una importante función de integración de las aferencias del córtex prefrontal (procesos atencionales, de evaluación y premotores), de la amígdala (integración emocional y autónoma) y del hipocampo (funciones mnésicas y de cartografía espacial). Si estas aferencias estimulan la corteza (shell) del núcleo accumbens de manera simultánea, ésta se activaría, confiriendo al contexto estimular un sello de "situación de valor adaptativo". En este estado, la porción interna (core) del accumbens -que es una extensión del estriado dorsal- dispararía grupos neuronales conectados con el córtex prefrontal, actividad que promovería la emisión de secuencias conductuales que permiten alcanzar de un modo seguro un objetivo concreto.

La repetición posterior de este proceso facilitaría tanto el reconocimiento contextual de la corteza como el perfeccionamiento de la secuencia de respuesta. Estos procesos dejarían de necesitar una activación dopaminérgica para desarrollarse, excepto si el estado motivacional es de privación de la conducta apetitiva (hambre, sed, celo) o al administrar drogas de abuso. En estos estados, existiría un aumento de la estimulación dopaminérgica que actuaría como un añadido "consolidante" de la secuencia conductual (6).

Resulta interesante subrayar las coincidencias que existen entre los resultados de estas investigaciones y la lectura que modelos como el de Tiffany (referidos a la comprensión del craving), realizan de las secuencias conductuales que median el abuso de drogas. Este autor propone que, tras la múltiple repetición de la conducta de consumo de drogas, ésta: a) se automatiza y ejecuta con rapidez y eficacia; b) resulta difícil de inhibir; c) se realiza sin apenas esfuerzo cognitivo, pudiendo completarse en ausencia de intención consciente; y d) las secuencias conductuales quedan almacenadas en registros de memoria a largo plazo $(7,8)$. En definitiva, se refiere a un mecanismo de aprendizaje implícito, que se realiza con independencia del intento consciente de efectuarlo.

Puede comprobarse que ambos modelos inciden en mecanismos de memoria implícita (inconsciente) en la conducta de abuso de drogas: desde un punto de vista neurobiológico el primero, y cognitivo, el segundo. Estos mecanismos pueden actuar de manera disociada respecto a la memoria consciente, pudiendo producir un aprendizaje inconsciente, como han mostrado los estudios sobre el efecto priming o los experimentos de aprendizaje bajo hipnosis farmacológica (9). La memoria implícita presenta varias características (10):

- Es un potente sistema de recogida de información.

- Se asienta en sistemas neurológicos evolutivamente más antiguos y que precedieron a los sistemas de memoria consciente.

- Emerge ontogénicamente antes que la memoria explícita.

- Presenta diferencias respecto a los sistemas de memoria explícitos:

- La memoria implícita soporta mejor que la explícita la desorganización derivada de posibles trastornos o enfermedades.

- La memoria implícita presenta una menor variabilidad intersujetos que la explícita.

- La edad y el cociente intelectual afectan en menor grado a la memoria implícita que a la explícita.

-El aprendizaje y la memoria implícita se expresan en todas las especies, mientras que la memoria explícita es fruto de la llegada de la conciencia al género humano.

La consideración de estos elementos abre interesantes hipótesis de trabajo que complementan el modelo de prevención de recaídas, al menos en las siguientes cuestiones. 
Es posible que el conjunto de "situaciones de alto riesgo" que precede a las recaídas esté relacionado, además de con elementos como la presión social o los estados emocionales negativos, también con contextos ambientales que, asociados a la historia personal de consumo de drogas, vuelven a presentarse en el momento actual. Así, Tulving propuso el término de "ecforia sinergística" (11) para señalar que el contexto en el que el sujeto se desenvuelve juega un papel tan fundamental para la ejecución de un acto (un consumo de drogas, por ejemplo) como el ambiente en el que se codificó la información. Los procesos de condicionamiento pavloviano, referidos por Rescorla como "aprendizaje que resulta de la exposición a relaciones entre eventos del ambiente" (12) parecen estar en la base de este condicionamiento contextual en el que estructuras subcorticales como el hipocampo $(13,14)$ juegan un papel fundamental para crear la representación de un ambiente que contiene no sólo un conjunto de estímulos, sino también las relaciones entre ellos.

Uno de los fenómenos más frecuentes en conductas adictivas, y que más complican la resolución del trastorno, es la ocurrencia de recaídas. El modelo de prevención de recaídas propone que, para realizar una adecuada recuperación, un sujeto debería ser capaz de detectar que se encuentra en una situación de riesgo y entonces realizar una respuesta de afrontamiento eficaz. Desde el punto de vista del funcionamiento cerebral, se plantea al paciente un sobreesfuerzo cortical para que de manera consciente detecte un contexto de riesgo, inhiba un patrón de respuesta que tiene muchas posibilidades de realizarse de manera automática y efectúe otra serie de operaciones comportamentales más adecuadas, denominadas "estrategias de afrontamiento". Quizás una de las dificultades en la realización de este proceso, que explica en parte la alta frecuencia de recaídas, provenga del propio diseño cerebral y de las conexiones entre sus diferentes regiones. Al plantear estas estrategias, se pretende ayudar a que la corteza controle áreas subcorticales como la amígdala, implicada en la activación emocional que ocurre durante el craving a drogas (15), sin ser quizás conscientes de la gran dificultad del proceso, ya que las conexiones que van del córtex a la amígdala son mucho más débiles que las que van de la amígdala a la corteza cerebral (14). Es posible que este diseño explique por qué la conducta de búsqueda de drogas se sobrepone con tanta frecuencia a los pensamientos conscientes y por qué cuesta tanto controlar la respuesta de craving.

Es posible también que los "ensamblajes celulares" que, durante la experiencia repetida de consumo de drogas, se crean en la amígdala (y entre la amígdala y otros circuitos cerebrales) en forma de conexiones neuronales reforzadas, dificulten los procesos de extinción de la respuesta de craving que se intentan inducir a través de técnicas de tipo conductual, como la exposición, o de tipo cognitivo, como las autoafirmaciones de afrontamiento (16). Es decir, como resultado de una larga historia de aprendizaje, las conexiones neuronales implicadas en la codificación de elementos contextuales del consumo de drogas y en la propia conducta de auto-administración podrían llegar a conectarse de forma más robusta en lo que se ha dado por llamar "potenciación a largo plazo" (17). Aunque se realice posteriormente una intervención de extinción que trate de eliminar la conducta de autoadministración, las conexiones neuronales en forma de los mencionados "ensamblajes celulares", o acoplamientos funcionales de neuronas que conservan cierta memoria pueden conservarse, manteniendo de esta manera una cierta "predisposición" que podría ser activada por cambios de intensidad en la señal de entrada al ensamblaje celular. El stress podría desempeñar esta función reactivadora, como vienen proponiendo algunos estudios $(18,19)$.

\section{SOBRE LA MENTIRA}

El tema de la mentira es una constante en el abordaje del fenómeno de las drogodependencias, contaminando muy frecuentemente la relación terapéutica con los pacientes. "Mentira" no sólo hace referencia a lo tocante al consumo de tóxicos; el engaño va más allá para introducirse en el mundo de la percepción del problema. De hecho, sorprende que un paciente niegue tener problemas con su pareja, con sus hijos o en su actividad laboral debido al consumo de alcohol (alteración de la conciencia central), y todavía sorprende más que llegue a crear una historia autobiográfica particular e irreal donde no parece existir problema alguno (alteración de la conciencia extendida) (20). En la intervención terapéutica resulta frecuente encontrarse con pacientes que engañan o mienten; de hecho, la causa última que lleva a tomar muestras de orina de los pacientes para su análisis es la desconfianza en sus afirmaciones.

La primera cuestión es por qué los pacientes mienten. La respuesta resulta simple: ¿qué obtienen diciendo la verdad? La psicología cognitiva plantea que un pilar básico para el tratamiento de los drogodependientes es que anticipen las consecuencias de su conducta, para que así actúen en consecuencia. Esto conduce a la segunda cuestión: ¿hasta dónde hay que anticipar? La variable tiempo en el funcionamiento cerebral es fundamental: si las consecuencias que se anticipan son negativas a corto plazo, se inhibe la conducta de la verdad.

Es un mecanismo de funcionamiento cerebral: mi cerebro tiene una imagen de lo que soy y de cómo soy; una imagen auto-protectora que compara los datos que llegan de la experiencia para expulsarlos si 
contradicen la imagen del yo, para mantener así mi status quo. Hay pacientes que evidentemente saben y conocen que están mintiendo, pero lo hacen para protegerse de las consecuencias de la verdad. Cuando un sujeto genera imágenes mentales sobre las consecuencias de ser sincero, estas imágenes generan una emoción negativa que inhibe la conducta, por lo que la mentira posee un valor adaptativo de preservación.

Este hecho parece bastante obvio; ahora bien, ¿qué hace que los sujetos defiendan con vehemencia "su verdad" y lleguen a creérsela?, ¿dónde están la verdad y la mentira en el cerebro?. Como decía Lord Byron, la mentira se convierte en una verdad inventada, lo que lleva a pensar que los conceptos de mentira y conciencia van inexorablemente unidos. De hecho podríamos afirmar, con Stuss y Benson $(21,22)$ que la conciencia, entendida como el ser consciente y no el estar consciente, es un atributo humano que permite darse cuenta de la propia realidad y de la posición en el entorno social, por lo que la mentira permite mantener el concepto de realidad y de status social. En este sentido, podría afirmarse que la falta de conciencia de un problema utiliza como un pilar básico de sustentación la verdad inventada, a fin de convertir la subjetividad en objetividad, con el propósito de que esa interpretación subjetiva, única y privada de mi realidad sea percibida por los demás como yo la percibo, lo que me permitirá mantener mi situación y, lo que es más importante, la imagen que tengo de mi mismo.

En este sentido, puede definirse la mentira como un autoengaño que refleja la falta de conciencia de un problema. De hecho, en la población alcohólica es frecuente encontrarse con pacientes que fabulan y crean historias explicativas sobre su problema que nada tienen que ver con la realidad. En este caso resulta difícil diferenciar qué parte de esta realidad puede ser atribuida a un déficit de memoria y cuál a la no aceptación de su responsabilidad en los problemas que el alcohol ha ocasionado en su vida. Estos pequeños matices llevan a la necesidad de diferenciar entre negación, minimización y falta de conciencia. Desde esta perspectiva, se ha planteado la conveniencia de considerar tres niveles de procesamiento en relación a este problema: uno relacionado con la información, otro neuropsicológico y un tercer nivel emocional. Este modelo tripartito (23) que se resume en la tabla anexa no resulta excluyente, por lo que en un mismo individuo podrían coexistir mecanismos de negación, minimización y falta de conciencia.

\begin{tabular}{|c|c|c|c|}
\hline $\begin{array}{l}\text { NATURALEZA } \\
\text { DE LA FALTA } \\
\text { DE CONCIENCIA }\end{array}$ & $\begin{array}{l}\text { INFORMACIÓN } \\
\text { NIVEL } 1\end{array}$ & $\begin{array}{c}\text { IMPLICACION } \\
\text { NIVEL } 2 \\
\text { NEUROPSICOLÓGICO }\end{array}$ & $\begin{array}{l}\text { INTEGRACIÓN } \\
\text { NIVEL } 3 \\
\text { EMOCIONAL }\end{array}$ \\
\hline $\begin{array}{l}\text { I. FALTA DE } \\
\text { CONCIENCIA }\end{array}$ & $\begin{array}{l}\text { 1. El paciente no tiene } \\
\text { información } \\
\text { 2. El paciente no tiene } \\
\text { conocimientos técnicos para } \\
\text { comprender el significado de } \\
\text { la información } \\
\text { 3. ¿Es la anosognosia un } \\
\text { síntoma? }\end{array}$ & $\begin{array}{l}\text { 1. El paciente no puede tomar } \\
\text { el "yo como objeto" } \\
\text { 2. El paciente no puede } \\
\text { comprender la información } \\
\text { 3. El paciente no puede } \\
\text { retener o recordar la } \\
\text { información } \\
\text { 4. Insuficiente arousal para la } \\
\text { conciencia }\end{array}$ & $\begin{array}{l}\text { 1. No hay implicaciones } \\
\text { emocionales }\end{array}$ \\
\hline $\begin{array}{l}\text { II. } \\
\text { MINIMIZACIÓN }\end{array}$ & $\begin{array}{l}\text { 1. No existen alteraciones a } \\
\text { nivel de información }\end{array}$ & $\begin{array}{l}\text { 1. El paciente no puede } \\
\text { comprender o abstraer de la } \\
\text { información sus consecuenc. } \\
\text { y/o implicaciones }\end{array}$ & $\begin{array}{l}\text { 1. El paciente conoce, pero } \\
\text { no soporta, el impacto de la } \\
\text { información, por lo que la } \\
\text { "reduce" a niveles de } \\
\text { tolerancia. }\end{array}$ \\
\hline III. NEGACIÓN & $\begin{array}{l}\text { 1. No existen alteraciones de } \\
\text { información }\end{array}$ & $\begin{array}{l}\text { 1. No se detectan } \\
\text { alteraciones neuropsicológ. } \\
\text { que expliquen el problema }\end{array}$ & $\begin{array}{l}\text { 1. El paciente no puede } \\
\text { creer la información, es } \\
\text { demasiado estresante y la } \\
\text { expulsa de su experiencia } \\
\text { consciente }\end{array}$ \\
\hline
\end{tabular}

Naturaleza de la alteración de la conciencia y niveles de procesamiento, modificado de Langer y Padrone 1992 (23). 
Trivers (24) ha sugerido una ingeniosa explicación de la evolución del autoengaño. Según él, en la vida cotidiana existen muchas situaciones en las que necesitamos mentir. En esta línea, otras investigaciones, como las de Ekman (25), han demostrado que los mentirosos, al menos que tengan mucha práctica, casi siempre se delatan con una sonrisa poco natural, una expresión de tensión o un falso tono de voz, que los demás pueden detectar. Esto se debe a que el sistema límbico (involuntario y propenso a decir la verdad) controla las expresiones espontáneas, mientras que las expresiones faciales que desplegamos cuando mentimos están controladas por la corteza (que no es solo responsable del control voluntario, sino que también es el lugar donde se inventan las mentiras). Para Trivers este problema tiene una solución: para mentir eficazmente a otra persona primero hay que mentirse a si mismo: si creemos que lo que afirmamos es cierto, nuestras expresiones serán auténticas, sin rastro de fingimiento. Sin embargo, esta afirmación encierra una contradicción interna, ya que contradice el propósito del autoengaño: un autoengaño implica que en algún momento puede tenerse acceso a la verdad; si no, el autoengaño dejaría de ser adaptativo.

Una manera de eludir este problema la plantea Ramachandran (26) cuando señala que una creencia no es necesariamente unitaria: es posible que el autoengaño se encuentre en el hemisferio izquierdo mientras el hemisferio derecho continúa "sabiendo" la verdad. Para este autor, la clave del autoengaño se encuentra en la división del trabajo entre los dos hemisferios cerebrales y en nuestra necesidad de crear una sensación de coherencia y continuidad en nuestras vidas. Es bien conocido que el cerebro consta de dos mitades simétricas, cada una de las cuales se encuentra especializada en diferentes capacidades mentales; la asimetría cerebral más notable corresponde al lenguaje. Además de estas divisiones conocidas de funcionamiento, Ramachandran sugiere que existe una diferencia aún más fundamental entre los estilos cognitivos de los dos hemisferios, lo que puede contribuir a explicar las modalidades de negación y de falta de conciencia. Por otra parte, Duffy (27) señala que la negación que pueden manifestar algunos pacientes afectados por abuso crónico de alcohol no tiene por qué ser interpretada como la consecuencia de una defensa maladaptativa del yo, sino como una manifestación de los efectos neurotóxicos del alcohol.

En este sentido, resultan reveladores los trabajos sobre el cerebro escindido llevados a cabo por Gazzaniga. Este autor ha estudiado una serie de pacientes con desconexión entre ambos hemisferios lo que permite conocer la información que guarda cada uno de ellos por separado. En uno de los casos paradigmático relatado por Ledoux, Wilson y Gazzaniga (28) -el caso P.S.- se pregunta al hemisferio izquierdo del sujeto qué desea hacer cuando termine el bachillerato a lo que responde "quiero ser delineante", mientras que cuando se realiza la misma pregunta al hemisferio derecho respondió: "autos de carrera". Este caso, como otros de la literatura, demuestra que ambos hemisferios cerebrales viven realidades diferentes y sugiere que cada uno puede llevar un cerebro mudo dentro de la cabeza con una realidad y con una percepción de sí mismo muy distinta de lo que diariamente cree ser.

En cualquier momento de la vida, el cerebro puede verse abrumado por una cascada continua de información que debe ser incorporada a una perspectiva coherente de la imagen propia y de lo que los demás esperan de uno. Para poder generar acciones coherentes o para mantener un status quo determinado, el cerebro debe disponer de algún mecanismo que permita cribar esta información y ordenarla en un esquema de creencias estable y con consistencia interna. De esto se encarga el hemisferio izquierdo: de integrar la información en la imagen previa del yo (29). ¿Qué ocurre cuando una información sobre la propia conducta no encaja en el guión establecido? El hemisferio izquierdo prescinde por completo de esa información, o bien, para mantener la estabilidad, la distorsiona para hacerla encajar en el marco preexistente. Lejos de ser defectos adaptativos, estos mecanismos cotidianos de defensa impiden que el cerebro se vea abocado a la incoherencia y a la falta de dirección por las múltiples posibilidades combinatorias de los guiones que pueden escribirse con el material que recoge nuestra experiencia. El inconveniente es que uno se miente a si mismo y a los demás, pero este precio resulta barato y asumible comparado con la coherencia y estabilidad que adquiere el sistema en su conjunto.

Las estrategias de adaptación empleadas por los dos hemisferios son básicamente diferentes. La tarea del hemisferio izquierdo consiste en crear un sistema de creencias, un modelo, y encajar toda nueva experiencia en ese sistema de creencias $(26,29)$. Al encontrar una información que atenta contra ese sistema de creencias recurre a la negación: reprime e inventa una historia que permita mantener el status quo. Sin embargo, la estrategia del hemisferio derecho consiste en actuar poniendo en tela de juicio ese status quo y buscar inconsistencias globales. Cuando la información anómala alcanza cierto umbral, el hemisferio derecho realiza una revisión global del modelo; es decir, el hemisferio derecho impone un cambio de paradigma. Este umbral es específico para cada individuo y depende de aspectos tan dispares como los rasgos de personalidad o el tipo de experiencia. Esto explicaría en parte por qué hay individuos que tras un ingreso hospitalario por un problema orgánico son capaces de aceptar su status de alcohólico y otros individuos lo niegan a toda costa, por qué hay individuos que aceptan su recaída tras la primera ocasión, 
mientras que otros precisan de múltiples ocasiones para llegar a tal aceptación.

\section{SOBRE LA VOLUNTAD}

En la labor clínica cotidiana es frecuente encontrar pacientes etiquetados como impulsivos, incapaces de anticipar las consecuencias de sus conductas, carentes de objetivos y planes a largo plazo, con dificultades para empatizar y con una falta evidente de motivación. Esta descripción, aplicable a muchos drogodependientes, plantea la duda de a que se refiere el concepto de motivación. Motivación podría ser definida, en principio, como la energía psíquica puesta a disposición de la realización de un acto agradable o la evitación de una conducta que a largo plazo puede tener efectos perniciosos. En este sentido, el concepto de motivación se halla muy cercano al concepto más clásico de voluntad, aunque este último presenta connotaciones más rígidas, estables y, si se quiere, morales.

Durante años se está trabajando con los adictos, intentando enseñarles -desde un modelo básicamente cognitivo- cómo anticipar las consecuencias de su conducta para intentar así inhibirla, sin haber deparado que el componente emocional es fundamental para que se produzca una potenciación de la motivación hacia el cambio y su mantenimiento. Evidentemente una imagen emocional negativa puede inhibir una conducta, pero al hacer referencia a imagen emocional se infiere que la imagen mental debe generar una emoción, un estado visceral que guíe el comportamiento. Desde esta perspectiva, en la clínica se observa cómo muchos pacientes conocen cómo deben actuar (porque así han sido enseñados con nuestra intervención cognitiva), pero no actúan como se espera de ellos. El motivo fundamental es que en el cerebro los procesos semánticos (cognición-conocimiento) y emocionales se pueden hallar disociados $(30,31)$. Como señalan Johns y Quay "los adictos conocen las letras de la emoción pero no su música" (32).

No sólo en nuestra intervención en drogodependencias, sino en otras áreas (como el trastorno límite o el trastorno disocial de la personalidad) es frecuente encontrarse con individuos incapaces de decidir lo bueno para ellos: no saben seleccionar una respuesta ventajosa en términos de supervivencia y calidad de dicha supervivencia. A pesar de ello, estos sujetos presentan una inteligencia intacta (33). Frecuentemente se plantea que inteligencia y voluntad son dos realidades indisolubles y que una inteligencia intacta equivale a una voluntad conservada, porque el sujeto conoce las consecuencias de su conducta. La inteligencia genera posibilidades de acción, pero la voluntad opera a través de las emociones para indicar la posibilidad más acertada para la supervivencia. La voluntad es la capacidad de seleccionar en función de los resultados a largo plazo, y no de las consecuencias a corto plazo; así, se fuerza la atención sobre el resultado negativo al que puede conducir una acción determinada enviando una señal de peligro que inhibe la conducta (33). En las adicciones se genera una respuesta primaria de deliberación: tras detectar un estímulo de recompensa, se responde a la presencia o ausencia de recompensa creando una predisposición y se genera un comportamiento de acercamiento (actitud apetitiva) hacia la fuente de recompensa.

En esta línea de argumentación, la hipótesis del marcador somático postulada por Damasio (34, 35, $36,37,38,39,40)$ trata de explicar la implicación de algunas regiones del córtex prefrontal en el proceso de razonamiento y toma de decisiones. Esta hipótesis se desarrolló buscando dar respuesta a una serie de observaciones clínicas en pacientes neurológicos afectados de daño frontal focal. Este grupo particular de pacientes no presentan defectos en el razonamiento, la toma de decisiones, la capacidad intelectual, el lenguaje, la memoria de trabajo o la atención básica; sin embargo, sus dificultades en el funcionamiento cotidiano son obvias, presentando severas dificultades en el dominio personal y social.

La hipótesis del marcador somático debe ser entendida como una teoría que trata de explicar el papel de las emociones en el razonamiento y toma de decisiones. Las observaciones de este autor señalan que pacientes con daño adquirido en la corteza prefrontal ventromedial realizaban adecuadamente los tests neuropsicológicos de laboratorio, pero tenían comprometida su habilidad para expresar emociones. Si, ante un perfil cognitivo conservado, el sujeto presenta dificultades en la toma de decisiones, ha de deducirse que el problema no sólo compete al procesamiento de la información, sino que deben existir otros aspectos o factores que están incidiendo en el problema.

Para intentar demostrar esta hipótesis se ha propuesto la prueba del "Juego de cartas" de Bechara $(33,41)$. Esta prueba consiste en un juego de cartas donde el sujeto tiene que levantar cartas de cuatro barajas diferentes $(A, B, C, D)$. Aunque el sujeto no lo sabe, con las barajas $A$ y $B$ se ganan cantidades variables de dinero con una media de ganancia por carta de 60 euros y se pierden cantidades variables con una media de pérdida de 75 euros. Por otro lado, con las barajas $C$ y D se ganan cantidades cuya media es de 30 euros por carta y se pierde una media de 24 . El juego concluye cuando se han levantado cien cartas. En la población control los sujetos levantan cartas al azar hasta el movimiento treinta aproximadamente, a partir del cual optan por jugar con las barajas C y D (decisiones ventajosas a largo plazo); los sujetos afectados por lesiones en el córtex prefrontal juegan con 
las barajas A y B o de forma caótica a lo largo de los 100 movimientos. La hipótesis más plausible para explicar estos resultados radica en que los sujetos normales, tras determinadas experiencias, pueden establecer balances que les conducen a tomar decisiones ventajosas a largo plazo, lo que no ocurriría en afectados por lesiones de la región ventromedial del córtex prefrontal ni en sujetos con trastorno disocial de la personalidad.

El planteamiento del marcador somático parte de algunas premisas o asunciones básicas: a) el razonamiento humano y la toma de decisiones dependen de múltiples niveles de operaciones neurobiológicas, algunas de las cuales son meramente cognitivas y otras no: las operaciones mentales dependen de imágenes sensoriales las cuales se sustentan en la actividad coordinada de áreas corticales primarias; b) todas las operaciones mentales dependen de algunos procesos básicos como la atención y la memoria de trabajo; c) el razonamiento y toma de decisiones depende de una disponibilidad de conocimiento acerca de las situaciones y opciones para la acción, conocimiento que está almacenado en forma de disposiciones en la corteza cerebral y en núcleos subcorticales; d) el conocimiento se puede clasificar como conocimiento adquirido (conocimiento acerca de hechos, eventos y acciones, que incluyen los estados corporales y las emociones y que se hacen explícitas como imágenes mentales) y conocimiento innato. La unión entre conocimiento innato y el conocimiento "acerca de" refleja la experiencia individual; la categorización de este conocimiento nos otorga nuestra capacidad de razonamiento (34).

Para Damasio la categorización contribuye a la toma de decisiones al clasificar tipos de opciones, posibles resultados y conexiones entre opciones y resultados. Piensa que este despliegue de conocimiento es posible sólo si se cumplen dos condiciones. Primera, se debe ser capaz de hacer uso de mecanismos de atención básica que permiten el mantenimiento de una imagen mental en la conciencia con la exclusión relativa de otras. Segunda, se debe poseer un mecanismo de memoria funcional básica, que mantiene imágenes separadas para un periodo relativamente extendido (de décimas a varios segundos) (42).

Cuando nos referimos a toma de decisiones, se presupone que quien decide posee conocimientos sobre la situación que requiere la decisión, sobre las distintas opciones de acción y sobre las consecuencias inmediatas y futuras de cada una de las opciones. En este sentido, el marcador somático forzaría la atención hacia las consecuencias de una acción determinada, funcionando como una señal de alarma automática ante lo inadecuado de algunas decisiones. Esta señal, básicamente emocional, puede llevar a rechazar inmediatamente el curso de acción, guiando hacia otras alternativas. Los marcadores somáticos se cruzan con las funciones ejecutivas en el campo de la deliberación, ya que resultan fundamentales para tomar decisiones, resaltando unas opciones sobre otras.

Desde la perspectiva de Damasio pueden plantearse algunas reflexiones para un acercamiento más adecuado al estudio de la voluntad y la motivación: algunas lesiones que afectan a la corteza prefrontal se hallan asociadas de manera consistente con alteraciones en el razonamiento-toma de decisiones y con la emoción-sentimiento (34); cuando el deterioro en razonamiento-toma de decisiones y en la emociónsentimiento destacan sobre un perfil neuro-psicológico conservado, el dominio personal y social es el más afectado. Existe una relación íntima entre razonamiento (cerebro) y emoción (cuerpo) ya que el organismo constituido por la asociación cerebro-cuerpo interactúa con el ambiente como un todo; es probable que los diferentes campos de conocimiento se representen en sectores prefrontales diferenciados; así, el dominio biorregulador y social parece tener mayor vinculación con los sistemas de la zona ventromedial.

El sistema neural crítico para la adquisición de señales de marcadores somáticos se halla en la corteza prefrontal, ya que la posición neuroanatómica de ésta es favorable para este propósito por las siguientes razones: a) recibe señales procedentes de todas las regiones sensoriales en las que se forman las imágenes que constituyen nuestros pensamientos, incluidas las cortezas somatosensoriales en las que se representan los estados corporales pasados y actuales; b) recibe señales desde varios sectores biorreguladores del cerebro entre los que se encuentran los núcleos neurotransmisores del tallo cerebral y del prosencéfalo basal, así como la amígdala, el cingulado anterior y el hipotálamo; y c) representa categorizaciones de las situaciones en las que el organismo se ha visto implicado, clasificaciones de las contingencias de nuestra experiencia vital. Las zonas de convergencia localizadas en la corteza prefrontal es así el depósito de representaciones disposicionales para las contingencias adecuadamente categorizadas y únicas de nuestra experiencia vital.

Además, puede postularse que un estado somático, positivo o negativo, causado por una determinada representación, opera no sólo como un marcador para el valor de lo representado, sino también como un amplificador para la atención y la memoria funcional continuadas. Los acontecimientos son energizados por señales que indican que el proceso ya se está evaluando, positiva o negativamente, en función de las preferencias, inherentes o adquiridas, del individuo.

En términos neuroanatómicos se sugiere que los marcadores somáticos, que operan en el ámbito biorregulador y social alineado con el sector ventromediano del córtex prefrontal, influyen sobre las 
operaciones de atención y de memoria operativa dentro de el córtex prefrontal dorsolateral, zona de la que dependen operaciones en otros ámbitos del conocimiento. Esto deja abierta la posibilidad de que los marcadores somáticos, que surgen a partir de una contingencia determinada expandan la atención y la memoria por todo el sistema cognitivo. Independientemente de cómo sean concebidas las funciones ejecutivas, Damasio considera que no debe ignorarse el problema de orden y propone que: a) si debe crearse orden entre las posibilidades disponibles, éstas deben estar jerarquizadas; b) si han de jerarquizarse, se precisa criterio; y c) los marcadores somáticos proporcionan criterios que expresan las preferencias acumulativas que se han ido adquiriendo y recibiendo.

Esta hipótesis resulta sugerente para explicar las conductas adictivas por diversos aspectos. Primero, por el papel que juega la hipoperfusión frontal en la falta de voluntad exhibida por los adictos $(43,44,45,46,47)$. Segundo, porque explica el escaso efecto que tiene la intervención cognitiva en el tratamiento. Y tercero, plantea la búsqueda de estrategias terapéuticas que tengan en cuenta las emociones para que se produzca un cambio estable en el sujeto.

\section{CONCLUSIONES}

La atención a drogodependientes está impregnada de prejuicios que con frecuencia interfieren en el trabajo terapéutico. Desde este artículo se pretende profundizar en la realidad de la adicción desde la perspectiva de las relaciones mente-cerebro. Especular sobre cómo situar los procesos mentales en el funcionamiento cerebral no pretende sino acercar el discurso sobre las adicciones al conocimiento de las neurociencias.

Este intento de acercamiento no debe conducir a posturas maximalistas ni deterministas: ni se justifican las conductas asociadas a la adicción por una irreversibilidad del funcionamiento cerebral ni se condenan las mismas porque dependen de la mente y por lo tanto de la voluntad. Debe superarse el dualismo cartesiano para plantear algo que, aunque obvio, no siempre es tenido en cuenta: cualquier acto mental y cualquier comportamiento humano se origina en un cerebro y en un cuerpo (48).

Es probable que los profesionales dedicados a este campo de intervención se pregunten por la utilidad de estos planteamientos en el trabajo cotidiano. Sin embargo, no se trata de buscar una aplicación directa de estas hipótesis sino de que sirvan en la comprensión de nuestros pacientes. Como señala Kandel: "la maquinaria neuronal del terapeuta produce un efecto en la maquinaria neuronal del paciente" (49). Si nuestro nivel interpretativo de la realidad produce un cam- bio en nuestra maquinaria neural, ésta puede orientarse en una dirección más positiva para conseguir un efecto positivo en la maquinaria neural del sujeto sentado frente a mí.

\section{REFERENCIAS BIBLIOGRÁFICAS}

(1) Marlatt GA. La prevención de recaídas en las conductas adictivas: un enfoque de tratamiento cognitivo-conductual. En Casas M, Gossop, M. (coord.), Recaída y prevención de recaídas. Ediciones en Neurociencias Barcelona. 1993.

(2) Marlatt A, Barret K. Prevención de recaídas: En Galanter MC, Kleber HD. (eds.), Tratamiento de los trastornos por abuso de sustancias. Masson. Barcelona. 1997.

(3) Park WK, Bari AA, Jey AR, Anderson SM, Spealman RD, Rowlett JK, Pierce RC. Cocaine administered into the medial prefrontal cortex reinstates cocaine-seeking behaviour by increasing AMPA receptor-mediated glutamate transmission in the nucleus accumbens. Journal of Neuroscience 2002; 22 (7): 2916-2925.

(4) Gerrits MA, Petromilli P, Westenberg HG, Di Chiara G, van Ree JM. Decrease in basal dopamine levels in the nucleus accumbens shell during daily drug-seeking behaviour in rats. Brain Research 2002; 924 (2): 141-150.

(5) Fernández-Espejo E. ¿Cómo funciona el nucleus accumbens? Revista de Neurología 2000; 30 (9): 845849.

(6) Fernández-Espejo E: Bases neurobiológicas de la drogadicción, Revista de Neurología, 2002, 34(7): 659-664.

(7) Ramos J, Tejero A, Trujols J. ¿Craving como elemento central o como epifenómeno en las conductas adictivas? Una revisión de la propuesta de Tiffany. Adicciones 1998; 10 (3): 217-221.

(8) Tiffany ST. A cognitive model of drug urges and drug-use behavior: role of automatic and nonautomatic processes. Psychological Review 1990; 97(2):147-168.

(9) Biescas J, Moix J, Casanovas P. Análisis de la memoria implícita durante la hipnosis farmacológica con propofol. Revista Española de Anestesiología y Reanimación 2000; 47(10): 458-463

(10) Ruiz Vargas J:M.: La memoria humana. Función y estructura. Madrid. Alianza editorial, 1994

(11) Tulving E.: Synergistic Ecphory in recall and recognition. Can J Psychology, 1982, 36:130-147.

(12) Rescorla R.A.: Pavlovian conditioning: It's not what you think it is. American Psychologist, 1988,43:151-160.

(13) Fortin NJ, Agster KL, Eichenbaum HB Critical role of the hippocampus in memory for sequences of events. Nature Neuroscience 2002; 5(5): 458-462.

(14) LeDoux J.: The emotional brain. New York. Simon \& Schuster. 1996

(15) Childress AR, Mozley PD, McElgin W, Fitzgerald J, Reivich M, O'Brien CP. Limbic activation during cueinduced cocaine craving. American Journal of Psychiatry 1999; 256: 11-18. 
(16) Sánchez-Hervás E. Estrategias para el manejo del craving (a drogas). Anales de Psiquiatría 2002; 18(1): 27-34.

(17) Hebb D.O.: the organization of behavior. New York. Wiley, 1949

(18) Lyvers M. "Loss of control" in alcoholism and drug addiction: a neuroscientific interpretation. Exp Clin Psychofarmacol 2000; 8(2): 225-249.

(19) Pineda J, Torrecilla M. Mecanismos neurobiológicos de la adicción a drogas. Trastornos Adictivos 1999; 1(1):13-21.

(20) Damasio A.R.,: The feeling of what happens. Body and emotion in the making of conciousness. Versión castellana: La sensación de lo que ocurre. Cuerpo y emoción en la construcción de la conciencia. Madrid. Debate, 2001

(21) Stuss D.T., Benson D.F.:The frontal lobes. New York. Raven Press, 1986.

(22) Stuss D.T., Benson D.F: Neuropsychological studies of the frontal lobes. Psychol. Bull. 1984,95:3-28

(23) Langer K.G., Padrone F.J.:Psychotherapeutic treatment of awareness in acute rehabilitation of traumatic brain injury. Neuropsychological Rehabilitation, 1992, 2,1:5970

(24) Trivers R.: Social evolution. Menlo Park,C.A.BenjaminCummings, 1985

(25) Eckman P.: Unmasking the face: Guide to recognizing Emotions from facial clues. Englewood Cliffs, N.J., Prentice Hall, 1975

(26) Ramachandran V.S.Blakeslee S.: Fantasmas en el cerebro. Madrid. Debate, 1999.

(27) Duffy J.D.: The neurology of alcohol denial: implications for assessment and treatment. 1995,40:257-263

(28) LeDoux J., Wilson D.H., Gazzaniga M.: A divided mind. Annals of neurology, 1977,2:417-421

(29) Goldberg E.: El cerebro ejecutivo: lóbulos frontales y mente civilizada. 2002. Barcelona. Crítica

(30) Hare Ry, Cox D: Clinical and empirical conception of psychopathy. En Hare R, Schalling D (Eds) Psychopatic behavior: approaches to research. Chischester: Wiley, 1978, 1-21,

(31) Christianson S, Forth $A E$, Hare RO et al: Remembering details of emotional events: a comparison betwen psychopathic and non psychopathic offenders. En Personality individual differences, 1996, 20.(4).437-443.

(32) Patrick CJ, Bradley MM, Lang PJ: Emotion in criminal psycopath: startle reflex modulation. J.Abn.Psychology, 1993, 102.(1).82-92.

(33) Tirapu-Ustárroz J, Suárez-González P, Millán J, MuñozCéspedes JM y Prado Santamaría C: Algunas reflexiones sobre el trastorno disocial: a propósito de un caso. An. psiquiatría, 2002, 18, 2: 87-92

(34) Damasio AR: Descartes' Error. Emotion, reason and the human brain. Putnam' Sons. New York. 1994.

(35) Damasio AR, Tranel D, Damasio H: Individuals with sociopathic behabiour caused by fronal damage fail to respond autonomocally to social stimuli. Behavioral Brain Research. 1990. 41: 81-94
(36) Damasio A.R., Tranel D., Damasio H: Somatic markers and the guidance of behavior: Theory and preliminary testing. En Levin H.S., Eisenberg H.M:, Benton A.L: Frotal lobe function and dysfunction. Oxford University Press.1991.

(37) Damasio A.R:, Damasio H:: Cortical systems for retrieval of concrete knowledge: the convergence zone framework. En Koch C.: Large-scale neuronal theories of the brain. MIT Press. Cambridge. 1995.

(38) Damasio A. R.: The somatic marker hypothesis and the possible functions of the prefrontal cortex. En:Roberts A.C., Robbins T.W., Weiskrantz L.:The frontal cortex: Executive and cognitive functions. Oxford University Press. 1998.

(39) Anderson, S.W., Bechara A., Damasio H., Tranel D, Damasio A.R.: Impairment of social and moral behavior related to early damage in human prefrontal cortex. Nature Neuroscience, 1999,2,111032-1037.

(40) Tirapu Ustárroz J, Perez Nievas F. Albeniz Ferreras A., Casi Arbonies A.: Validez ecológica de las pruebas neuropsicológicas de los procesos ejecutivos: a propósito de un caso. An. Psiquiatría, 1997,13,8:339-344.

(41) Bechara A., Damasio A.R., Damasio H., Anderson S.W.: Insensitivy to future consequences following damage to human prefrontal cortex. Cognition, 1994, 50:7-15.

(42) Tirapu Ustárroz J, Muñoz Céspedes JM, Pelegrín Valero

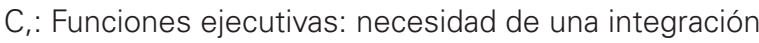
conceptual. Revista de Neurología, 34(7):673-685.

(43) Volkow ND, Wang GJ, Fowler JS, Hitemann R, Angrist B, Gatley SJ, et al. Association of metilphedinate-induced craving with changes in right striato-orbitofrontal metabolism in cocaine abusers: implications in addiction. Am J Psychiatry 1999;156:19-26.

(44) Netrakom P, Krasuski JS, Miller Ns et al: Structural and functional neuroimaging findings in substance-related disorders. Psychiatr Clin North Am, 1999. 22(2)313-29

(45) Chang L, Ernst T, Strickland T et al: Gender effects on persistent cerbral metabolite changes in the frontal lobes of abstinent cocaine users. Am J Psychiatry 1999. 156.716-722

(46) Kosten TR, Cheeves C, Palumbo J, Seibyl JP, Price LH, Woods SW. Regional cerbral blood flow during acute and chronic abstinence from combined cocaine-alcohol abuse. Drug and alcohol dependence 1998;50:187-195.

(47) Stein EA, Pankiewicz J, Harsch HH, Cho JK, Fuller SA, Hoffmann RG, et al.Nicotine-induced limbic cortical activation in the human brain: a functional MRI study. Am J Psychiatry 1998;155:1009-1015.

(48) Tirapu-Ustarroz J, Muñoz-Céspedes JM: Aportaciones de la neuropsicología a la psicología clínica". 2002, En prensa.

(49) Kandel ER: Biology and the future of psychoanalysis: a new intellectual framework for psuchiatry revisited. Am j Psychiatry 1999. 156(4):505-524. 